\title{
Investigation and Countermeasures of Primary and Middle School Students with Poor Self- Discipline in Online Teaching
}

\author{
Huan-Song Yang, Yue-Han Qiao*, Shao-Li Zhang, Zhang Nan \\ Hangzhou Normal University \\ Hangzhou 311121, China \\ *Corresponding Author
}

\begin{abstract}
Since the beginning of 2020, due to the impact of the epidemic, the state has advocated "suspension of classes and non-stop learning". Due to the large differences in primary and secondary students' personalities, online teaching has a great impact on different primary and secondary students' teaching effects. Matthew effect is very obvious. It is worth pondering how to conduct online teaching for students who are not conscious in learning and have poor self-regulation ability. Based on a questionnaire survey and interviews with students who are not self-conscious and have poor self-discipline ability, this paper conducts relevant practical research and puts forward corresponding suggestions and countermeasures to improve the teaching effect of online teaching.
\end{abstract}

Keywords—god beast; online teaching; practical research

\section{INTRODUCTION}

Since the end of December 2019 wuhan outbreak a pneumonia, 31 provinces in China launched a response, in order to further ensure the security of life between teachers and students, on January 27, 2020, the Ministry of Education issued a circular to delay the spring opening time [1], and on January 29th, issued a "suspended class, keep learning" initiative [2], local department of education, schools are actively carry out online teaching activities, in epidemic situation to meet the needs of the students' learning, this is the beginning of online teaching. For the children who were able to manage themselves and complete their learning tasks under parental supervision did not have a significant impact on their learning and were able to continue on a regular basis. However, for the children who are weak in self-consciousness, unable to conduct good self-management and do not listen to their parents' Suggestions and opinions (these children are called "god beasts" by social people), the effect of online teaching is worth thinking about. In view of this part of students who are called "beasts of God"

The project was supported by the postgraduate education reform project of hangzhou normal university

"Practice and exploration of graduate classroom teaching reform based on minimalist education technology" (YJG201908)

National major research and development project: multi-modal natura interaction of virtual and real integration of open experimental teaching environment (2018YFB10044900)

Think tank construction project: "Internet + new mode of talent cultivation for scientific and creative information application", no. PD16005002002

2019 project of hangzhou normal university: a study on classroom teaching in the context of new media technology by social personages, we have carried out relevant practical research, and put forward relevant suggestions and countermeasures, in order to further improve the learning effect of this part of students.

\section{DEFINITION OF RELEVANT CONCEPTS}

1. God beast: especially refers to some children who are lively, have poor self-consciousness and self-control, and do not listen to their parents' words.

2. Online teaching: online teaching is different from offline teaching. It is a new teaching form to break through the limitation of time and space by using Internet technology and relying on network learning resources, tools, platforms and space to realize non face-to-face and long-distance teaching between teachers and students.

\section{PRACTICAL RESEARCH}

\section{A. Research Purpose}

The purpose of this study is to understand the influence of online teaching on this part of students who are called "god beast", and to propose relevant Suggestions and countermeasures, so as to further promote the learning of this part of students.

\section{B. Research Object}

The research object of this study is 50 students from class 2 and class 3 of junior high school in XX city, XX province. The teachers of these 50 students are the same. Under the condition of consistent teaching methods and teaching plans in the previous offline face-to-face teaching, their scores are relatively stable and there is not much difference. The online teaching teachers are still the same teachers, and the teachers use the "multi-group broadcast" function in the "Ding Talk" platform to teach. In this study, with the help of the teachers, the 50 students with the same level were divided into two groups. The second group was composed of 25 students with weak self-control and unconscious learning ability. 


\section{Data Analysis}

Through statistical analysis of the original data, the data are shown below.

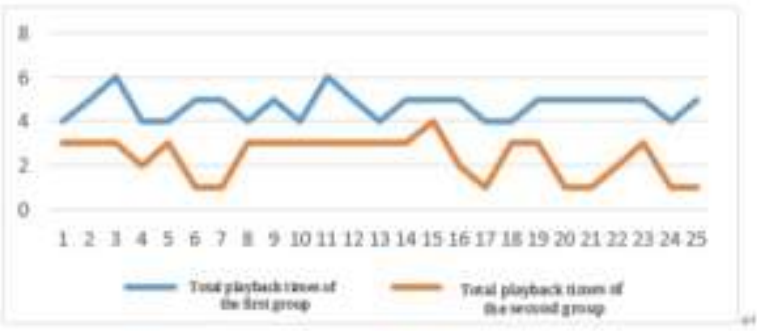

Fig. 1. Total playback times

As can be seen from figure 1, the total number of replays of the five live broadcasts of the first group of students was concentrated in the range of 4-6, and 9 students had 4 replays, 14 students had 5 replays, and 2 students had 6 replays. In the second group, the total playback times of 5 live broadcasts were about 1-4 times, and there were 7 students with one replay time, 3 students with two replays, 14 students with three replays, and 1 student with four replays.

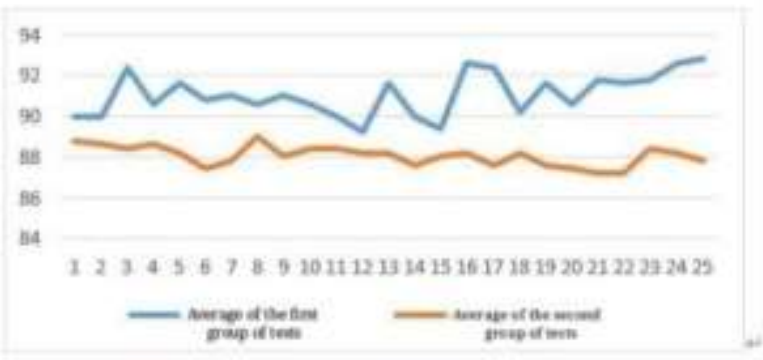

Fig. 2. Test averages

As can be seen from figure 2, the average of five tests of the first group of students was between 89-93, among which 23 students scored above 90, while 2 students scored below 90 and above 89 . In the second group, the average of five tests was between 87 and 89 , with one student scoring 89 .

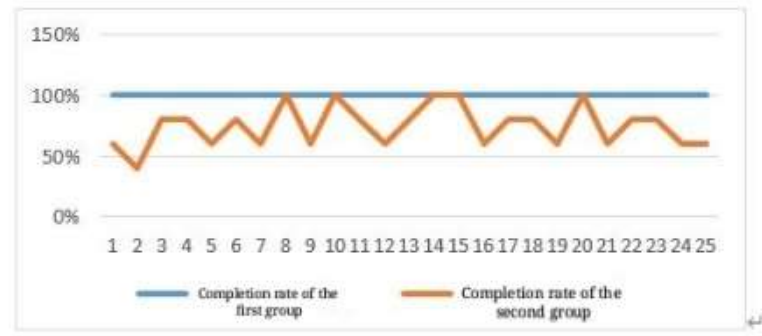

Fig. 3. Job completion rate

According to figure 3, the completion rate of 5 homework assignments of the first group was $100 \%$. In the second group, the completion rate of five homework assignments was concentrated in the range of $40 \%-100 \%$, among which there were 5 students whose homework completion rate was $100 \%$.

\section{ThOUGHTS}

\section{Existing Problems}

\section{A. Online Teaching Widens the Gap between these Students and Students of the Same Level}

According to figure 1 and figure 3 , the learning initiative and enthusiasm of the second group of students are lower than that of the first group, and according to figure 2, the average test value of the second group of students is lower than the average test value of the first group of students, which shows that online teaching has a great impact on the learning of the second group of students, namely the "god beast" students.Therefore, for the students who are similar to the second group of students' personality characteristics, online teaching makes them unable to complete the learning task better,which will cause some knowledge faults after the opening of this part of students group, and it is difficult to adapt to the learning content.

\section{B. Online Teaching Makes the Parent-child Relationship of these Students More Tense}

According to the results of the interview, it can be found that the parents of the second group of students are prone to conflict with their children due to learning problems, and the parent-child relationship is more tense. And even lead some parents to simply let go and let them develop freely. In addition, due to the impact of the recent comprehensive return to work, parents can't supervise their children and can only rely on the elderly, while "next generation parents" make the elderly unable to restrain their children, resulting in more slack learning of children, forming the vicious cycle model shown in Figure 4 below.

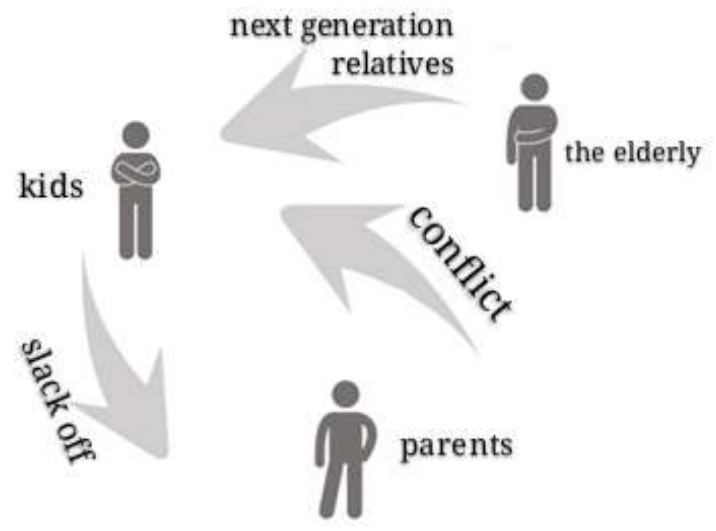

Fig. 4. Relational cycle pattern

\section{Online Teaching Reduces the Intimacy between Teachers and Students}

During offline teaching, teachers can pay attention to every student in the class, give timely reminders to some students with low consciousness, ensure that these students with low consciousness can also complete their learning tasks well. After online teaching, teachers can't have a clear judgment on this part of students' learning state, nor can they remind students in time, They can only rely on the cold screen for a few 
communication and exchanges, which leads to less intimacy between teachers and students, This is not good for teaching activities.

\section{SUGGESTIONS AND COUNTERMEASURES}

\section{A. Schools and Teachers should Strive to Implement the "One} Life Policy"

The "one policy for life" mentioned by the author here refers to the teaching strategies that are most beneficial to each student according to their specific characteristics. For example, some students involved in this study who are not aware of learning can be helped by schools and teachers. At the same time, teachers can change the teaching mode in the classroom, shorten the teaching time in the classroom, leave some time for students to simply summarize and share the lesson on their own, in addition, they can add some game content, for example, by setting up "scoreboard" and other ways to motivate students.

\section{B. Parents should Communicate Patiently and Supervise Reasonably}

For this part of children, on the one hand, parents should do a good job in the role of supervisor, at the same time, in this process, children's consciousness and self-discipline should be further developed. On the other hand, even if the child does not listen to the parents, the parents should be patient in communicating with the child, and timely reflect the problems in communication. After the parents return to work, they also need to communicate with the elderly to form a joint force, strictly implement the established plan.

\section{To Strengthen the Interaction between Teachers and Students and Enhance the Sense of Intimacy}

According to the practical research and interviews, at present, more than $80 \%$ of the teachers in this junior high school surveyed by the author use the way of online live broadcast to complete the teaching. Therefore, teachers should strengthen the interaction with students in and out of class, only when the relationship between teachers and students, home and school is more and more intimate, can teachers and students achieve better cooperation to overcome learning difficulties together.

\section{CONCLUSION}

Online teaching is the most appropriate teaching method under the current situation of epidemic situation, which speeds up the construction of digital education in China to a large extent, but also exposes many problems. This research is aimed at the students who have poor consciousness and are not obedient. It is found that online teaching has a great influence on this part of students, and the main influence has widened the gap between them and the students at the same level, further leading to the tension between their parents and children; reducing the intimacy between teachers and students is not conducive to the development of teaching activities, and some suggestions are put forward Policy, that is, schools and teachers should strive to implement the "one life policy", parents should be patient communication and reasonable supervision, teachers and students should strengthen interaction, and improve intimacy. Teaching is always a process of continuous progress, which requires efforts from all aspects. Schools, teachers, parents, including students themselves, only by combining and cooperating with all aspects of strength, can we truly achieve the educational goal and make students grow into pillars.

\section{REFERENCES}

[1] Notice of the Ministry of education of the people's Republic of China on the postponement of the opening of the spring semester 2020 [EB/OL].http://www.moe.gov.cn/jyb_xwfb/gzdt_gzdt/s5987/202001/t20 200127_416672.html,2020-01-27.(In Chinese)

[2] Ministry of education. Ministry of Education: using the Internet platform "no suspension of classes"

EB/OL].http://www.moe.gov.cn/jyb_xwfb/gzdt_gzdt/s5987/202001/t20 200129_416993.html,2020-01-29. (In Chinese).

[3] Yang H S, Wu J P. Exploration on Cultivation of Application-Oriented and Innovative Talents in the Information Field under "Internet+" Environment $[\mathrm{J}]$. Eurasia Journal of Mathematics, Science \& Technology Education, 2017, 13(8): 5607-5614.

[4] Jiaping Wu, Zhuping Wang, Huansong Yang. Education data collection, data quality analysis and data preprocessing [J/OL]. Journal of Ningbo Institute of Education, 2016, 18(06):62-65.

[5] Yang HS,Wang MY,Wu JP.Research on Multiple Complex Data Processing Methods Based on OpenStack Cloud[J].International Journal of Advanced Engineering Research and Science, 2017,4(4):15-20

[6] Abuzaghleh, O., Goldschmidt, K., Elleithy, Y., et al.Implementing an affordable high -performance computing for teaching -oriented computer science curriculum[J]. ACM Transactions on Computing Education (TOCE),2013(13):1. 